\title{
Anatomical and Functional Changes in the Organization of the Cuneate Nucleus of Adult Rats after Fetal Forelimb Amputation
}

\author{
Robert W. Rhoades,' John T. Wall,' ${ }^{1}$ icolas L. Chiaia,' ${ }^{1}$ Carol A. Bennett-Clarke, ${ }^{1}$ and Herbert P. Killackey ${ }^{2}$ \\ 'Department of Anatomy, Medical College of Ohio, Toledo, Ohio 43699-0008 and '2Department of Psychobiology, \\ University of California at Irvine, Irvine, California 92717
}

A previous study has shown that fetal forelimb removal in the rat results in an increase in the size of the hindlimb representation in primary somatosensory cortex and suggested that this anomalous cortical organization may have resulted from alterations in the primary afferent innervation of the dorsal column nuclei (Killackey and Dawson, 1989). The present study used both anatomical and electrophysiological techniques to examine the effects of fetal forelimb amputation on the dorsal column nuclei. Rats sustained forelimb removals on embryonic day 16 and were used in terminal experiments when they reached adulthood ( $>60 \mathrm{~d}$ of age). Analysis of cytochrome oxidase-stained sections demonstrated that the cuneate nucleus ipsilateral to the lesion decreased in volume by an average of $36.7 \%(N=7$, $p<0.001$, paired $t$ test), but there was no corresponding increase in the volume of the gracile fasciculus and nucleus. Bilateral application of HRP to the sciatic nerves demonstrated that axons that innervate only the gracile nucleus on the intact side of the brainstem were present in the cuneate nucleus on the deafferented side. Injection of HRP into the skin overlying the point of the amputation (the stump) indicated that axons innervating this region filled most of the dorsal one-half of the shrunken cuneate nucleus and overlapped with the sciatic nerve afferents innervating the cuneate on this side. Mapping the receptive fields of multiple unit clusters demonstrated that most recording sites in the shrunken cuneate nucleus were activated by inputs from the stump and adjacent skin. In addition, $9.1 \%(N=30)$ of such unit clusters $(N=328)$ could also be excited by stimulation of the hindlimb. These were observed in only three of the nine experiments. Unit clusters with split receptive fields including the skin overlying the stump and the hindlimb were located throughout the rostrocaudal extent of the cuneate nucleus. These results indicate that fetal forelimb amputation results in anatomical expansion of the central projections of hindlimb afferents into the cuneate nucleus. This anatomical organization appears weakly expressed in the receptive fields of cuneate neurons.

[Key words: primary afferents, horseradish peroxidase,

\footnotetext{
Received June 30, 1992; revised Sept. 2, 1992; accepted Sept. 22, 1992.

This work was supported by NS 28888 , DE 08971 , DE 07734, NS 21105 , and BNS 90-22168. The excellent technical assistance of Sandra K. Rasey, Beth Figley, and Marcia Eck is gratefully acknowledged.

Correspondence should be addressed to Dr. Robert W. Rhoades, Department of Anatomy, Medical College of Ohio, P.O. Box 10008, Toledo, OH 43699-0008. Copyright (C) 1993 Society for Neuroscience $0270-6474 / 93 / 131106-14 \$ 05.00 / 0$
}

axonal sprouting, transneuronal degeneration, somatosensory system, development]

The rodent somatosensory cortex contains a discrete and parcellated representation of the entire body surface that can be demonstrated with a variety of histochemical and neuroanatomical tracing techniques (e.g., Woolsey and Van der Loos, 1970; Welker, 1976; Killackey and Belford, 1979; Dawson and Killackey, 1987; Jensen and Killackey, 1987). These representations have also been demonstrated in the ventrobasal thalamus (VB), and in both the trigeminal (V) brainstem complex and dorsal column nuclei (DCN) (Van der Loos, 1976; Woolsey and Wann, 1976; Belford and Killackey, 1979; Land and Simons, 1985). In the trigeminal portion of this sensory system, there is considerable evidence that the organization of these cortical representations is altered by neonatal manipulations of the periphery and, further, that the cortical changes follow closely and are determined by alterations in the brainstem (for reviews, see Killackey et al., 1990; Woolsey, 1990).

The present experiments explored the developmental relationship between the brainstem and cortex in the dorsal column component of the somatosensory system. In this portion of the somatosensory system, hindlimb and forelimb afferents project to separate brainstem targets, respectively, the gracile and cuneate nuclei. This organization allows assay of interactions between distinct components of the somatosensory system during the course of development. In a recent study, Killackey and Dawson (1989) amputated the forelimbs of fetal rats and used histochemical techniques to assay the representation of the body surface in the primary somatosensory cortex. In animals that sustained forelimb amputations on embryonic day (E) 16, there was a nearly $100 \%$ increase in the cortical area devoted to the hindlimb. Killackey and Dawson (1989) suggested that this enlarged cortical hindlimb representation reflected alterations at the level of the brainstem. More specifically, they proposed that primary afferents from the hindlimb innervate both the gracile nucleus, their normal target, and some or all of the cuneate nucleus. The aim of the present experiment was to test directly the proposal of Killackey and Dawson (1989) by using transganglionic tracing techniques to label hindlimb-related primary afferents and electrophysiologic methods to map the representation of the body surface in the DCN of adult rats that sustained forelimb amputations on E-16.

\section{Materials and Methods}

Forelimb amputations. Timed pregnant dams obtained from Harlan Sprague-Dawley were anesthetized with ether on the 16th embryonic day (E-16; sperm positive day $=\mathrm{E}-0$ ). A $25 \mathrm{~mm}$ incision was made 
through the skin and muscular abdominal wall along the linea alba approximately $5 \mathrm{~cm}$ above the vagina. The muscular wall was refiected and the uterine horns were exteriorized. The uterine sac containing each fetus was stabilized between the blades of blunt forceps and transilluminated with the aid of a fiber optic light source. The uterine wall and amniotic sac were pierced with a microknife, and either the left or right forelimb was excised. Following limb amputation, the blade of the microknife was withdrawn and pressure was applied to the incision site with a cotton swab to arrest leakage of the amniotic fluid. The uterine horns were then replaced in the abdominal cavity, and the overlying abdominal wall and skin were sutured. Pups were allowed to come to term and survive at least $60 \mathrm{~d}$ before they were employed in experiments. A summary of the numbers of animals in the different experiments comprising this study is provided in Table 1 .

Primary afferent labeling. Adult rats that sustained unilateral forelimb amputations on E-16 were anesthetized with a combination of ketamine $(100 \mathrm{mg} / \mathrm{kg})$ and xylazine $(20 \mathrm{mg} / \mathrm{kg})$. In two animals, the central terminations of primary afferents innervating the stump and immediately adjacent region were labeled by injection of $60 \mu \mathrm{l}$ of a cocktail containing $20 \%$ wheat germ agglutinin-conjugated horseradish peroxidase (HRP) and $2.0 \%$ cholera toxin-conjugated HRP, using a Hamilton microsyringe.

In seven animals, hindlimb-related primary afferents were labeled by injecting $10 \mu \mathrm{l}$ of the same tracer cocktail directly into the sciatic nerve in each leg. In these animals, the skin overlying the lateral thigh was incised and the sciatic nerve was followed from its emergence at the sciatic notch to the level of the mid-thigh. The tracer was delivered via a glass capillary syringe (Drummond Microtrol Syringe) in three successive penetrations of the nerve. The wound was then closed with silk sutures.

Following injections, animals were returned to their home cages. After a survival period of 3-4 d, rats were killed with a lethal dose of sodium pentobarbital $(60 \mathrm{mg} / \mathrm{kg}$ ) and perfused transcardially with physiological saline followed by a solution containing $4 \%$ paraformaldehyde in phosphate buffer ( $\mathrm{pH}$ 7.4). The brainstem and spinal cord were removed and postfixed overnight in a $4 \%$ paraformaldehyde solution containing $10 \%$ sucrose in phosphate buffer. The brainstem of each animal was cut into $50 \mu \mathrm{m}$ coronal sections, and alternate sections were processed for HRP reaction product according to a modification of the tetramethylbenzidine protocol of Mesulam (1978). The remaining sections were processed for cytochrome oxidase according to the method of WongRiley (1979).

Analysis of the volume of the dorsal column nuclei. Cytochrome oxidase-stained sections from seven animals used in the HRP tracing experiments were employed to assess the effects of fetal forelimb amputation on the volume of DCN. Sections containing the DCN were magnified with a tissue projector and drawn at a total magnification of $63 \times$. The areas of the cuneate nucleus and the combined fasciculus and nucleus gracilis were computed with the aid of a graphics tablet. The tract and nucleus were combined for the latter measurements because of the difficulty in defining the borders of the gracile nucleus relative to the overlying tract in many sections. Volumes were determined by multiplying cross-sectional areas by $100 \mu \mathrm{m}$ (twice the section thickness). The data from the intact and partially deafferented sides of the brainstem were compared by paired $t$ tests.

Electrophysiological mapping. Standard multiple-unit recording and receptive field mapping techniques were used to assess the representation of the body surface on both sides of the dorsal medulla of nine rats that sustained fetal forclimb amputations and two normal animals. Rats were anesthetized with ketamine $(100 \mathrm{mg} / \mathrm{kg})$ and xylazine $(20 \mathrm{mg} / \mathrm{kg})$ and placed in a stereotaxic head holder. A midline incision was made in the skin over the rostral brainstem, and the neck muscles were freed from their occipital attachments and reflected. Portions of the occipital bone were removed with a rongeur, and the dura overlying the brainstem was incised and reflected to expose the rostral medulla from a point approximately $1-2 \mathrm{~mm}$ rostral to the obex to the first cervical vertebra. The surface of the brainstem was photographed at $44 \times$ to record the placement of microelectrode penetrations and then covered with warm silicone to prevent drying.

Mapping was accomplished using procedures described by Wall and Cusick (1984). Briefly, unit clusters and occasional single units were recorded with varnish-coated tungsten microelectrodes $(Z=0.9-1.3$ $M \Omega)$. Cutaneous receptive fields were defincd with tactile stimuli delivered to the skin and hairs with brushes and blunt probes. In addition to responses to cutaneous stimuli, responses to harder tapping of the
Table 1. Summary of the different experiments comprising this study

\begin{tabular}{llllll} 
Rat & Rec. & $\begin{array}{l}\text { Sciatic } \\
\text { nerve } \\
\text { label }\end{array}$ & $\begin{array}{l}\text { Stump } \\
\text { label }\end{array}$ & $\begin{array}{l}\text { Rec. }+ \\
\text { sciatic } \\
\text { label }\end{array}$ & $\begin{array}{l}\text { Rec. }+ \\
\text { stump } \\
\text { label }\end{array}$ \\
\hline Normal & 2 & 0 & 0 & 0 & 0 \\
Exp. & 6 & 5 & 1 & 2 & 1
\end{tabular}

A total of 2 normal and 15 fetally manipulated (Exp.) animals were used. In each case where the sciatic nerve was labeled, injections were made on both the normal and damaged sides. Rec., recording.

body surface were also noted. Regions of the skin from which responses were evoked were plotted on drawings made from photographs of the body surface.

In the two normal rats and three of the experimental animals, we sought to determine the overall organization of the functional representation of the body surface in the dorsal medulla. In these experiments, electrode penetrations spaced $200 \mu \mathrm{m}$ apart were made in a roughly rectangular array across both the intact and partially deafferented sides of the brainstem. Recordings were made at the surface and at each 200 $\mu \mathrm{m}$ in depth until units unresponsive to tactile stimulation were noted. In these experiments, particular attention was paid to determining the lateral and medial borders for the representation of the skin overlying the stump. In the remaining $(N=6)$ experimental animals, the region containing the representation of the skin overlying the stump was sampled at a higher density. Electrode penetrations were spaced approximately $100 \mu \mathrm{m}$ apart, and the receptive fields of unit clusters were mapped at $100 \mu \mathrm{m}$ intervals in depth. Onc of these mapping experiments used an animal that had injections of HRP into the sciatic nerve, and one employed a rat that received an HRP injection into the skin overlying the stump.

Several electrode tracks in each experiment were marked either with electrolytic lesions or by using an electrode that had been dipped in a fluorescent dye. At the end of each mapping experiment, the animal was given a lethal dose of pentobarbital $(80 \mathrm{mg} / \mathrm{kg})$ and perfused in the manner described above. Brainstems were removed and histologically processed as described above.

\section{Results}

Extent of forelimb amputations. Most of the animals had a short $(<10 \mathrm{~mm})$ stump of bone and muscle in the vicinity of the shoulder. This stump was covered by hairy skin that was not detectably different from normal chest skin and contained no scars. Other than this stump, the forelimb was absent.

Shrinkage of the cuneate nucleus. Fetal forelimb amputation resulted in significant shrinkage of the cuneate nucleus ipsilateral to the amputation, but no corresponding changes in the size of the gracile fasciculus and nucleus. Cytochrome oxidase-stained sections from the brainstem of a rat that sustained amputation of the left forelimb are shown in Figure 1, and measurements of the volumes of the cuneate nucleus and gracile fasciculus and nucleus on both sides of the brainstem are summarized in Table 2. Fetal forelimb amputation resulted in a $36.7 \%$ decrease in the volume of the cuneate nucleus. The difference between the volumes of the cuneate nuclei on the two sides of the brainstem was statistically significant $(t=9.34$, $\mathrm{df}=6, p<0.001$, paired $t$ test), whereas the gracile volume on the deafferented side was $99.2 \%$ of the volume of that on the intact side $(t=0.35, \mathrm{df}=$ $6, p>0.05$, paired $t$ test).

Primary afferent innervation of the cuneate nucleus. Injection of HRP into the skin overlying the stump of the amputated forelimb in each of two rats resulted in transganglionic labeling of the dorsal to central one-half of the cuneate nucleus (Fig. 2). Thus, the skin overlying the stump and that immediately adjacent to it was represented throughout a substantial portion of 

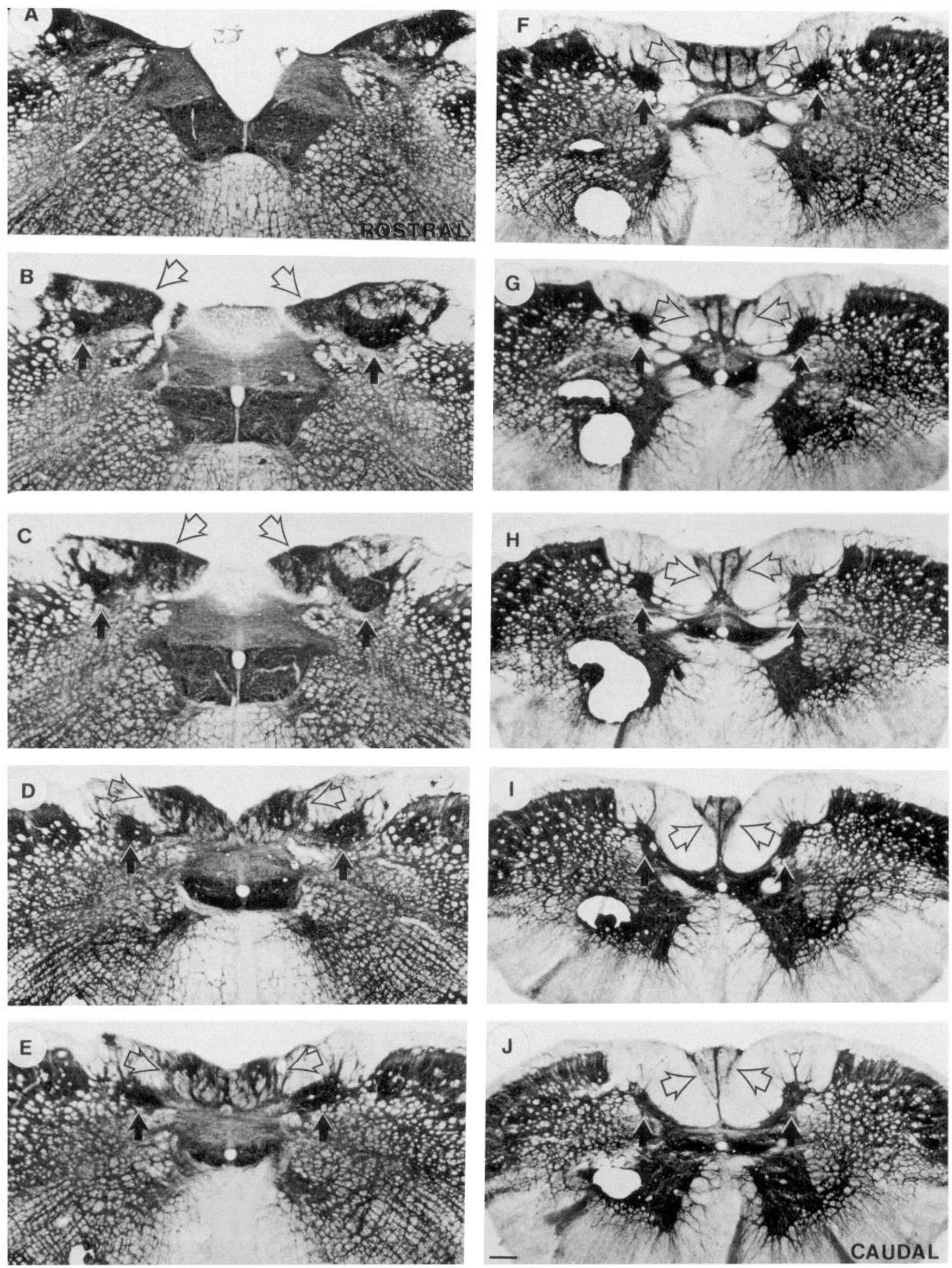
the shrunken cuneate nucleus on the partially deafferented side of the brainstem.

The sciatic nerves were bilaterally labeled in seven rats. Ipsilateral to the normal forelimb, nucleus gracilis was densely labeled but no label was observed in the cuneate nucleus (Fig. 3 ). In contrast, ipsilateral to the amputation, the label in the gracilis nucleus extended laterally into the cuneate nucleus (Fig. 4). The density of sciatic labeling in the cuneate nucleus was quite variable and was generally correlated with that in the adjacent fasciculus and nucleus gracilis. In the most heavily labeled cases, sciatic nerve axons encompassed nearly the entire rostrocaudal extent of the cuneate nucleus, but the labeling was generally more dense rostrally, dorsally, and medially. In two animals with heavy labeling of the fasciculus and nucleus gracilis, labeling of the cuneate nucleus was more sparse (Fig. 5). Regardless of the density of label in the cuneate nucleus, the sciatic label clearly overlapped with the label seen after injection of HRP into the skin overlying the stump, particularly in the dorsal, medial, and central parts of the cuneate (compare Figs. 2, 4).

Representation of the body surface in the partially deafferented cuneate nucleus. Initial mapping experiments at low sampling density (i.e., $200 \mu \mathrm{m}$ ) revealed an orderly representation of the body surface in the brainstem or the normal rats and on both the intact and deafferented sides of the brainstem of amputated rats (Fig. 6). On the normal side of the amputated rats (results from these animals did not differ from those provided by the two unoperated rats), progressions from medial to lateral resulted in movement of receptive fields from the tail and hindpaw to the trunk, the forelimb, and finally to the face. Ipsilateral to the amputation, the progression was similar. The hindpaw and tail were represented at the most medial recording sites, and progressively more lateral recording sites had receptive fields on the trunk, the skin overlying the stump, and finally on the head and face.

The results of these low sampling density experiments suggested that the stump fields overlapping the shoulder, chest, and neck activated a significant portion of the normal forelimb representation, as indicated by the fact that stump recording sites were localized in mirror-symmetric positions to the forelimb representation on the contralateral normal side. None of the rows of penetrations on the deafferented side of the brainstem demonstrated a region in which the hindlimb and face representations were directly adjacent. A representation of the skin overlying the stump was invariably interposed. These data thus indicate that hindlimb-related primary afferents did not functionally dominate the shrunken cuneate nucleus on the partially deafferented side of the brainstem.

In light of the anatomical findings presented above, the results of these initial mapping experiments were surprising. Therefore, we carried out additional more detailed mapping experiments focused on the cuneate nucleus and sampled neuronal responsiveness at $100 \mu \mathrm{m}$ intervals. Six animals with fetal forelimb removals were employed in these experiments, and the results from the case with the greatest overlap between the stump and hindlimb representations on the deafferented side of the medulla
Table 2. Volumes of the cuneate nucleus and the gracile fasciculus and nucleus on the intact and deafferented sides of the brainstem of adult rats that sustained amputation of one forelimb on E-16

\begin{tabular}{|c|c|c|c|c|}
\hline \multirow[b]{2}{*}{ Rat } & \multicolumn{2}{|c|}{ Vol. $\mathrm{n}$. cuneatus $\left(\mathrm{mm}^{3}\right)$} & \multicolumn{2}{|c|}{$\begin{array}{l}\text { Vol. n. and } \\
\text { f. gracilis }\left(\mathrm{mm}^{3}\right)\end{array}$} \\
\hline & Intact & $\begin{array}{l}\text { Deaf- } \\
\text { ferented }\end{array}$ & Intact & $\begin{array}{l}\text { Deaf- } \\
\text { ferented }\end{array}$ \\
\hline $91-20$ & 0.174 & 0.108 & 0.219 & 0.216 \\
\hline $90-7$ & 0.160 & 0.107 & 0.248 & 0.252 \\
\hline $91-19$ & 0.182 & 0.117 & 0.280 & 0.245 \\
\hline $92-1$ & 0.203 & 0.112 & 0.173 & 0.166 \\
\hline $91-21$ & 0.183 & 0.129 & 0.331 & 0.350 \\
\hline $90-4$ & 0.228 & 0.156 & 0.228 & 0.239 \\
\hline $91-17$ & 0.262 & 0.152 & 0.190 & 0.185 \\
\hline $\bar{X}$ & 0.199 & 0.126 & 0.238 & 0.236 \\
\hline SD & 0.035 & 0.021 & 0.054 & 0.060 \\
\hline
\end{tabular}

The difference between the average volumes of the cuneate nuclei on the two sides was significant $(t=9.34, \mathrm{df}=6, p=0.000009$, paired $t$ test). The slight difference between the volumes of the gracile fasciculi and nuclei on the two sides was not statistically significant $(t=0.35, \mathrm{df}=6, p=0.74$, paired $t$ test).

are illustrated in Figure 7. In this experiment, a long rostrocaudally oriented set of penetrations was made in the cuneate nucleus. Unit clusters with receptive fields on the skin overlying the stump or regions closely adjacent to it were recorded in 17 of the 20 penetrations and at 75 sites in this animal. Responses to stimulation of the hindlimb were recorded in seven tracks and a total of 19 recording sites.

Three of the six experimental animals that were mapped in detail had unit clusters with split receptive fields of the type illustrated in Figure 7 . In the three animals with such fields, their pereentages relative to the number of sites at which unit clusters responsive to the stump or immediately adjacent skin were $2 \%, 10 \%$, and $25 \%$. Overall, we recorded from 328 unit clusters responsive to the skin overlying or immediately adjacent to the stump. Of these, only $9.1 \%(N=30)$ had receptive fields that also included the hindlimb or immediately adjacent skin.

While it was not the aim of the experiment to record isolated single units and map their receptive fields, recordings at three locations suggested that stump and hindquarter afferents may have converged onto single cuneate neurons (Fig. 8). All three of these reasonably well-isolated units responded to stimulation of the skin overlying the stump. One (Fig. $8 A$ ) also responded to stimulation of hairs in the pelvic region, and two (Fig. $8 B, C$ ) were responsive to stimulation of the hindpaw. The histology for the recording site of the neuron whose responses are depicted in Figure $8 C$ is shown in Figure 9. The marking lesion is in the center of the cuneate nucleus.

In summary, the anatomical results indicate a variable but highly abnormal input from hindlimb primary afferents to the ipsilateral cuneate nucleus following fetal forelimb removal. Given the diminished size of the cuneate nucleus and the location of labeled terminations, these hindlimb afferents almost certainly overlap the distribution of primary afferents arising

\footnotetext{
Figure 1. Bright-field photomicrographs of a series of cytochrome oxidase-stained sections showing the reduction of the size of the cuneate nucleus ipsilateral to the fetal forelimb amputation. The sections are spaced at approximately $200 \mu \mathrm{m}$ and arranged in a rostral $(A)$ to caudal $(I)$ sequence. The deafferented side is on the left, and the solid arrows point to the cuneate nucleus on each side. Note that the cuneate nucleus is reduced in
} size, but that it still remains distinct from the gracile nucleus (indicated by the open arrows). Scale bar, $250 \mu \mathrm{m}$. 

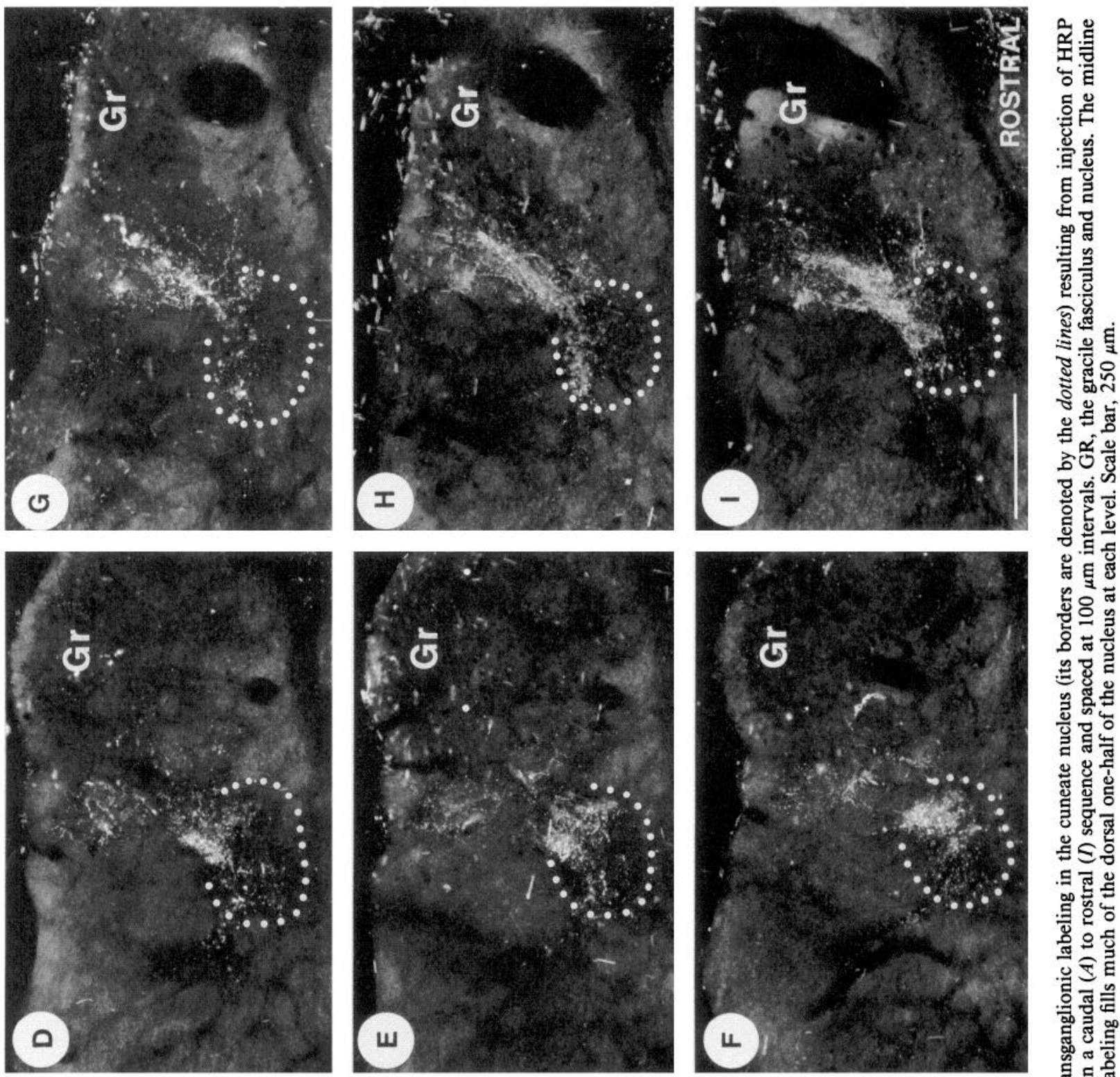

율

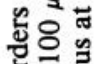

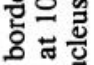

응

品

एँ

灵宁址

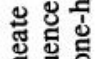

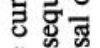

Ð5응

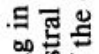

응

远옹

오음

즘

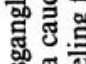

总
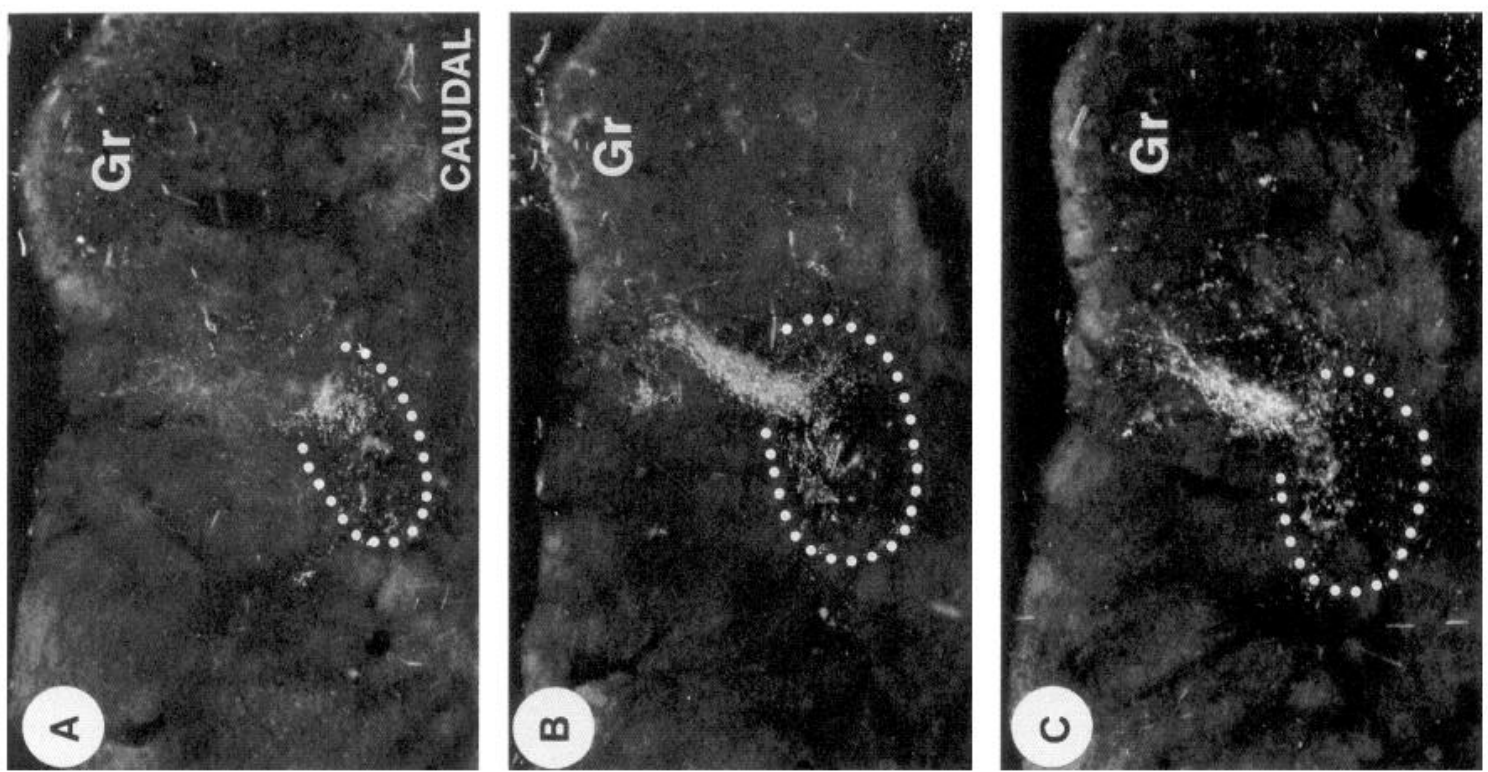

o.

등해음

ज्ञ

跑

o

응

光

항

훙음

물

क क

흠

of

존

등

웅. 동

ن

今o

这. 

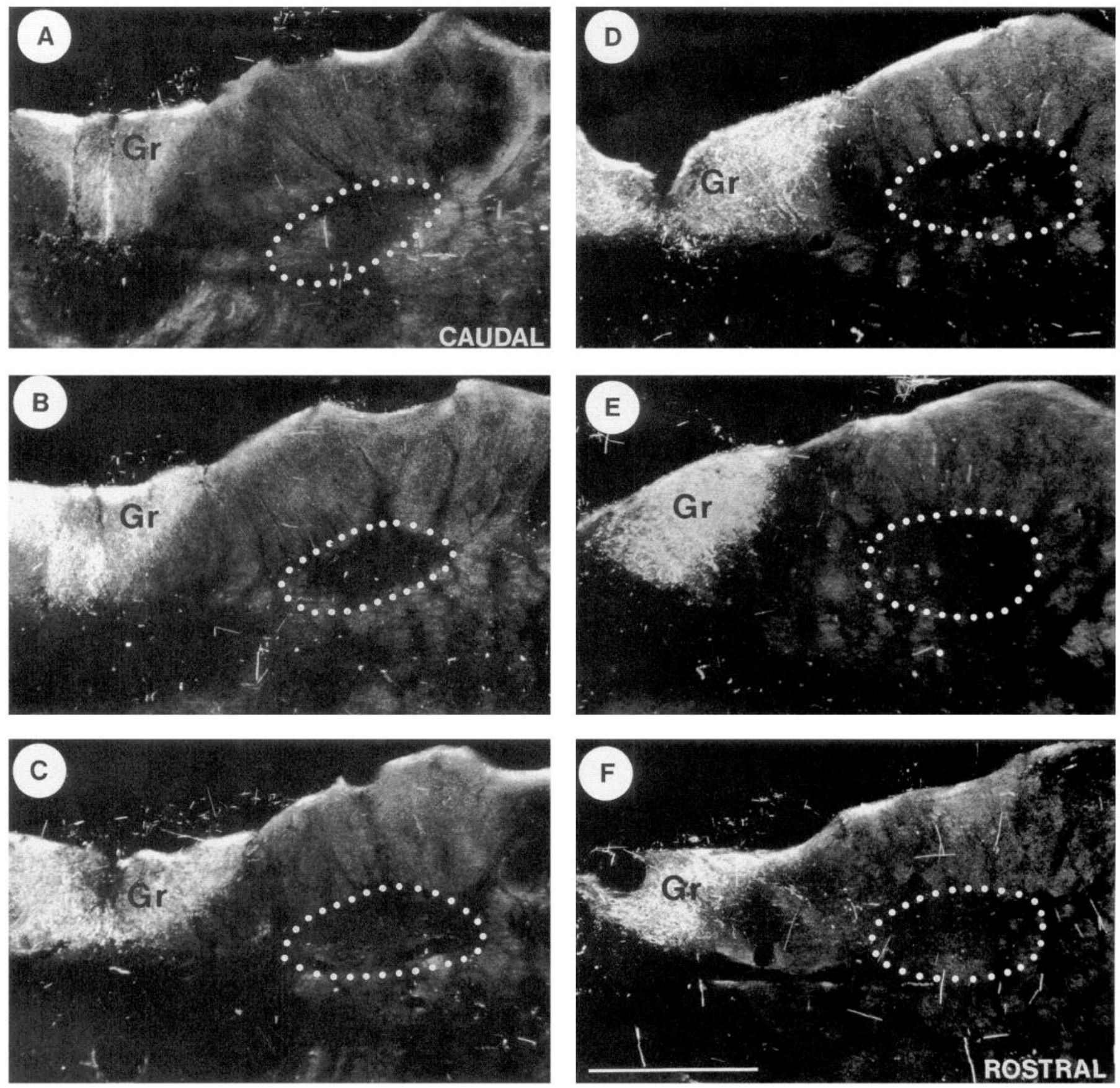

Figure 3. Transganglionic labeling resulting from application of HRP to the sciatic nerve of an adult rat that sustained amputation of the ipsilateral forelimb on E-16. The sciatic nerve on the intact side was labeled. The sections are arranged in a caudal $(A)$ to rostral $(F)$ sequence and spaced at $200 \mu \mathrm{m}$ intervals. The borders of the cuneate nucleus are denoted by the dotted lines; Gr, the gracile fasciculus and nucleus. Note that no labeled fibers extend into the cuneate nucleus. Scale bar, $250 \mu \mathrm{m}$.

from the forelimb stump. The physiological results provide some support for the convergence of hindlimb- and forelimb-related primary afferents in the shrunken cuneate nucleus, but indicate that the larger part of this nucleus becomes functionally dominated by inputs from the skin around the stump.

\section{Discussion}

The present findings indicate that fetal forelimb amputation in rat results in a shrunken cuneate nucleus that is innervated by both a novel input from the sciatic nerve and a functionally (and perhaps also anatomically) expanded input from proximal regions surrounding the amputated forelimb. The electrophysiological experiments demonstrate that a small proportion of unit clusters and perhaps also single cells within the altered cuneate nucleus receive functionally convergent input from the hindlimb and stump, but that most sites within this nucleus are functionally dominated by inputs from the stump and adjacent skin.

Shrinkage of the cuneate nucleus. One previous study has reported that early limb removal results in a reduction in size of the associated DCN (Johnson et al., 1972), and similar transganglionic atrophy has been reported in the brainstem trigem- 

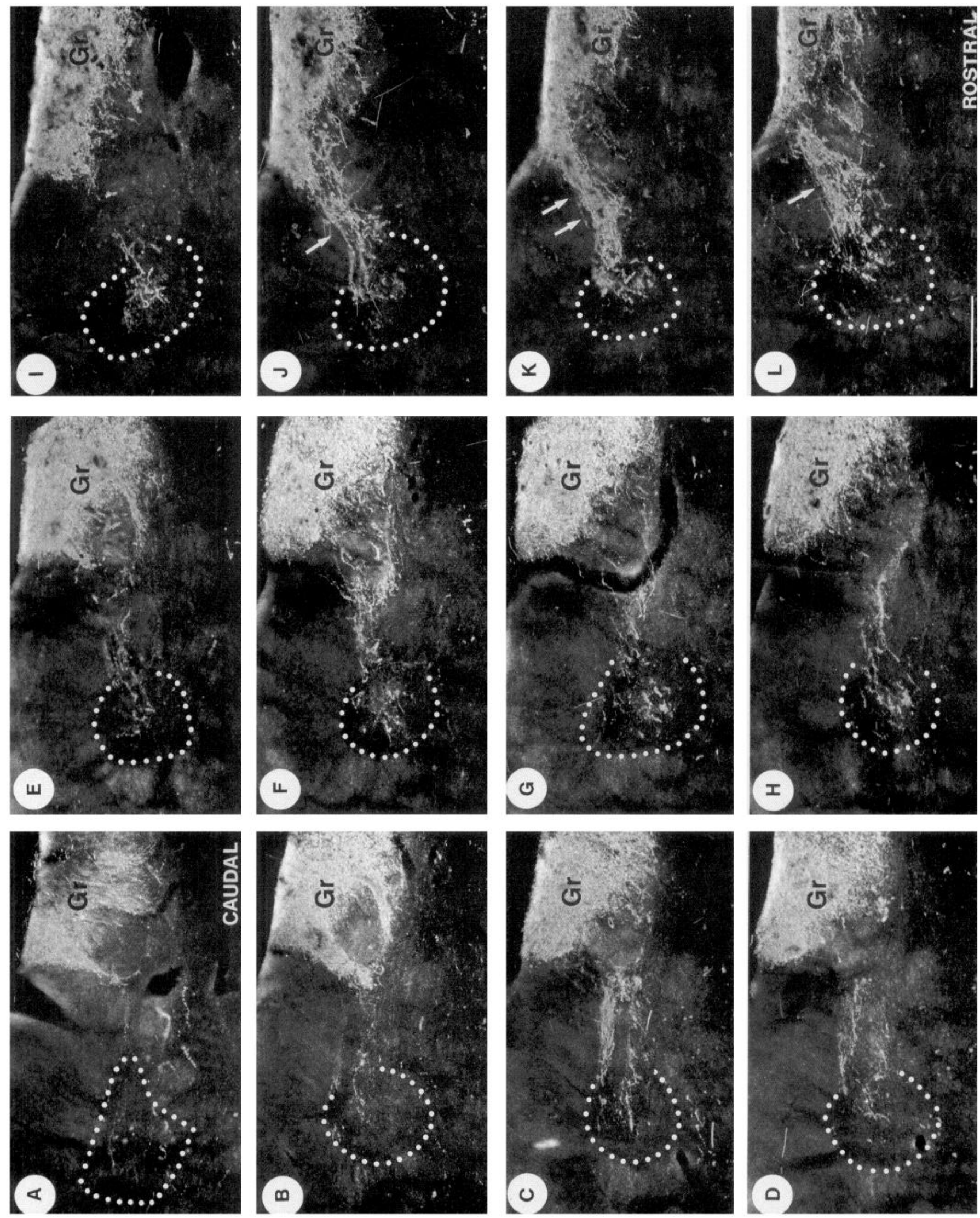

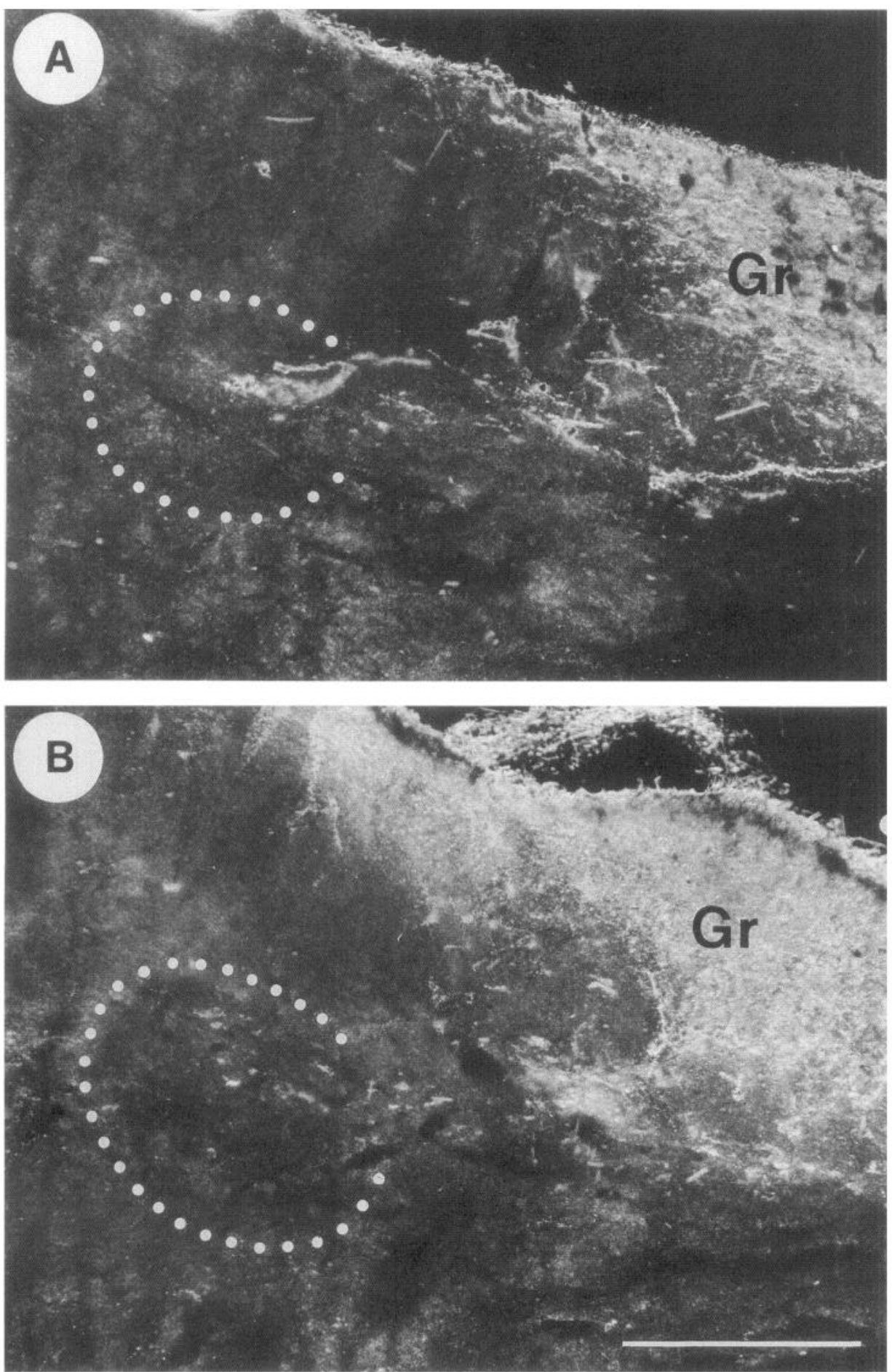

Figure 5. Dark-field photomicrographs showing sections from two cases in which the sciatic nerve on the side of the limb amputation was heavily labeled, but where only a few labeled axons extended into the cuneate nucleus, which is indicated by the dotted lines. Scale bar, $250 \mu \mathrm{m}$. inal system after neonatal infraorbital nerve section (see Jacquin and Rhoades, 1985, for review). In the present study, the volume of the cuneate nucleus was reduced to approximately two-thirds of normal size following forelimb amputation. This reduction was not accompanied by any detectable volume change in the adjacent gracile nucleus and fasciculus. We attribute this to the fact that the manipulation probably did not alter the number of primary afferent neurons whose axons comprise the fasciculus gracilis (Killackey and Dawson, 1989).

The border between the two DCN was well demarcated in the adult animals that sustained fetal forelimb amputations (however, see Killackey and Dawson, 1989, for somewhat dif-

Figure 4. Transganglionic labeling resulting from application of HRP to the sciatic nerve of an adult rat that sustained amputation of the ipsilateral forelimb on E-16. The sections are arranged in a caudal $(A)$ to rostral $(L)$ sequence and spaced at $100 \mu \mathrm{m}$ intervals. The borders of the cuneate nucleus are denoted by the dotted lines; $G r$, the gracile fasciculus and nucleus. Note the extension of labeled sciatic primary afferents into the medial one-half of the cuneate nucleus. This is especially apparent in $J-L$ (arrows). Scale bar, $250 \mu \mathrm{m}$. 

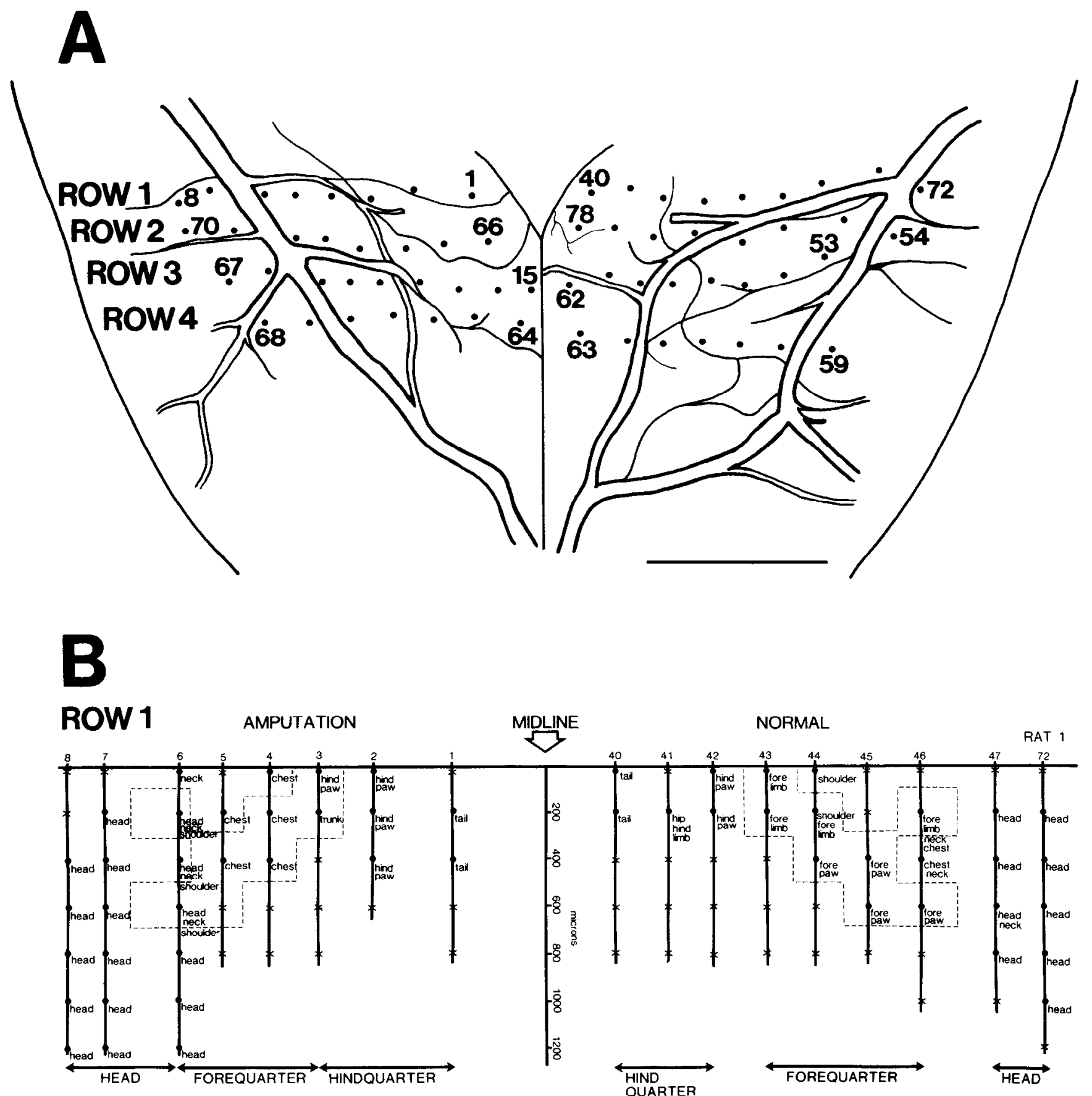

Figure 6. Results of a typical mapping experiment in the medulla of an adult rat that sustained amputation of the forelimb on E-16. The data summarized are from 78 penetrations spaced at approximately $200 \mu \mathrm{m}$ intervals in four rows across the intact and deafferented sides of the brainstem $(A)$. The receptive field data obtained in each row of penetrations are summarized in $B$. In each row on the intact side, there is a mediolateral progression from unit clusters with receptive fields on the tail to the hindlimb, then the trunk, then the forelimb, and finally the face. A similar progression was noted on the deafferented side with the important difference that the region normally devoted to the forelimb now contained a representation of the shoulder (i.e., stump). The dashed lines denote the regions in which unit clusters responsive to stimulation of the chest, shoulder, and/or forelimb were recorded. $x$, locations of points where neuronal activity could not be driven by cutaneous stimuli. Scale bar in $A$, $1 \mathrm{~mm}$.

ferent results from animals examined shortly after birth). It is possible that the apparent lack of interaction between the two components of the DCN may have resulted from the fact that intrinsic developmental events have proceeded to the point that these nuclei are essentially separate compartments by the time of the forelimb amputation (E-16). This would suggest the pe- ripheral input may not play a role in subdividing groups of brainstem neurons into discrete nuclei. Alternatively, it must be remembered that our lesions did not remove all of the normal primary afferent innervation of the cuneate nucleus and it may be that this reduced input was sufficient to "instruct" qualitatively normal compartmentalization. 
ROW 2 ampUtATION
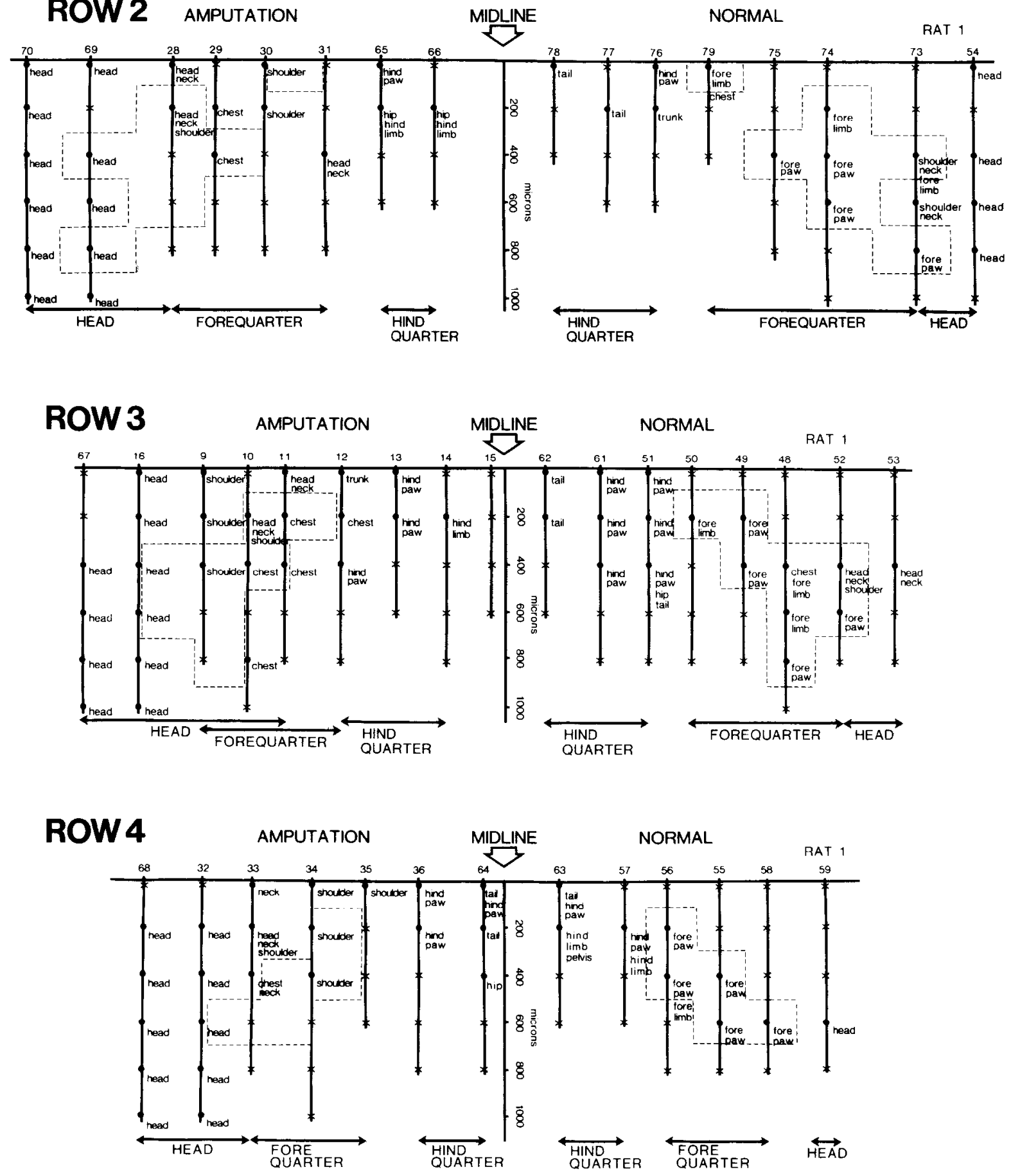

Figure 6. Continued.

Anomalous primary afferent projections to the cuneate nucleus. We provide evidence for two projections to the altered cuneate nucleus. The first can be regarded as normally targeted in that its peripheral origin is appropriate for the cuneate nucleus. However, this projection appeared to be expanded into locations normally representing the amputated parts of the distal forelimb. The second projection arises from the sciatic nerve and varies in density from case to case. In the densely labeled cases, the sciatic nerve also projected to a considerable portion of the altered cuneate nucleus. While we made no attempt to measure the degree of overlap between these two projections, it is clear that they do so. Our evidence, albeit limited, of functional convergence within the altered cuneate nucleus supports this contention.

The sciatic projection into the cuneate nucleus most probably reflects an alteration of the initial ingrowth of sciatic axons into the DCN. Chimelli and Scaravilli (1987) showed that primary afferent axons labeled by injection of HRP into the rat hindlimb reach the region of the gracile nucleus on E-17 and penetrate it on E-20. They noted no termination of fibers labeled by hind- 
Figure 7. Results from an experiment in which a more detailed mapping of the region including the stump representation on the deafferented side of the brainstem was carried out. Each of the symbols on the dorsal view drawing of the brainstem denotes the location of an electrode track in which unit clusters were recorded at $100 \mu \mathrm{m}$ intervals (in depth) until two unresponsive sites in a row were encountered. The solid circles denote points at which unit clusters with split receptive fields that included both the stump and a portion of the hindlimb were recorded. Examples of the split receptive fields plotted for unit clusters in each of these penetrations are shown on the left. The open triangles denote points with unit clusters that included the stump, but in which there was no representation of the hindlimb. The dashed line indicates the midline. Scale bar, $1 \mathrm{~mm}$.
Figure 8. Examples of apparently single units from the cuneate nucleus ipsilateral to fetal forelimb amputations with split receptive fields. Each unit is from a different rat, and the blackened areas on the figurines show the cells' receptive fields. In each case, the first trace ( 1 ) shows the response to stimulation (denoted by arrows below the traces) of the stump. The second trace (2) shows the response to stimulation of the hindlimb (or pelvis in $A$ ), and the third (3) depicts the unit's spontaneous activity. The calibration is $0.2 \mathrm{mV}$ by 2 sec. The drawing shows the location of a lesion marking the cell whose responses are shown in $C$ ( $C u$, cuneate nucleus; $G R$, gracile fasciculus and nucleus; $V$, trigeminal subnucleus caudalis; the open arrow points to the midline). Scale bar, $250 \mu \mathrm{m}$.
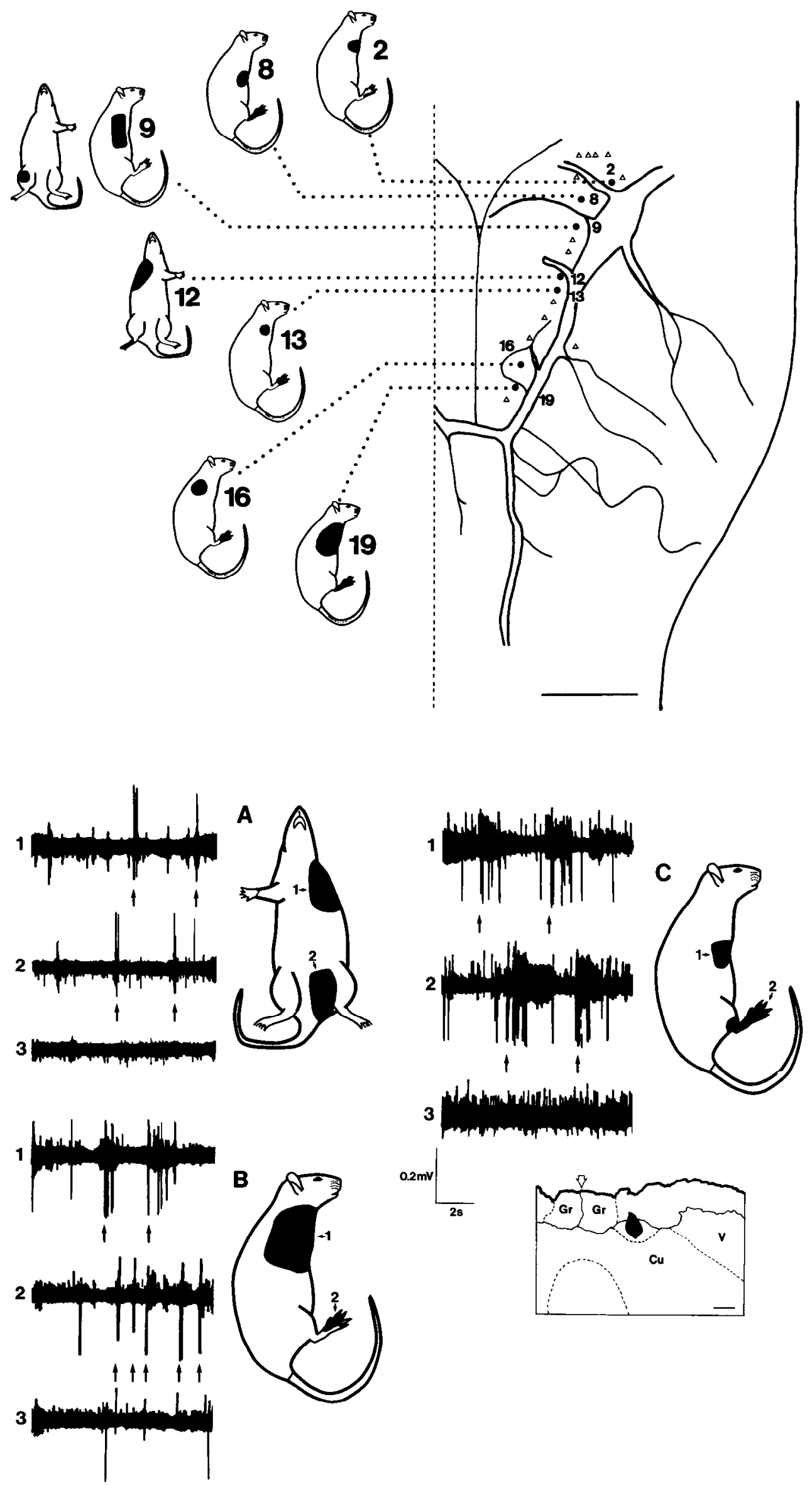


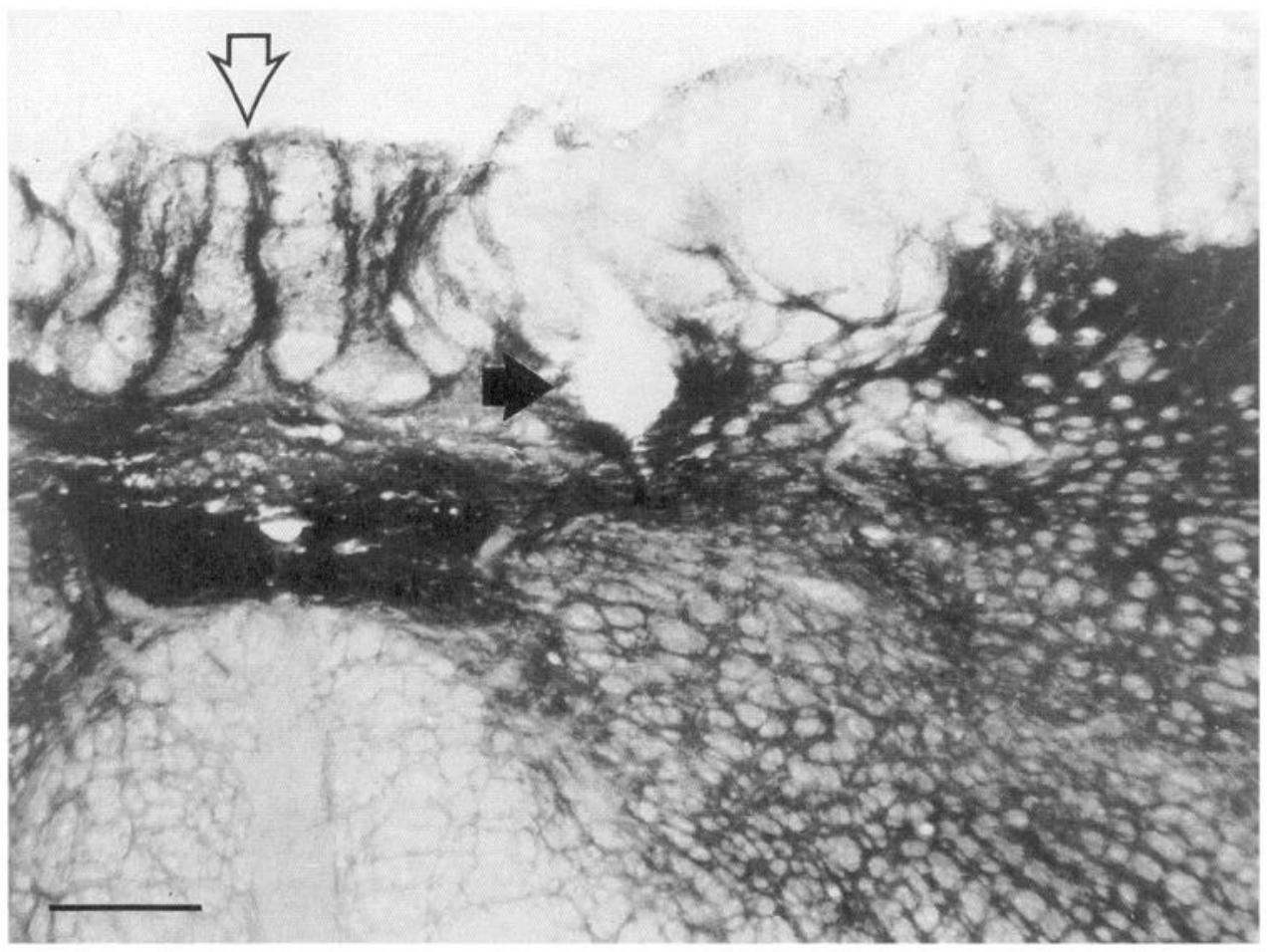

Figure 9. Photomicrograph of the section used to make the drawing in Figure 8. The solid arrow points to the location of the electrolytic lesion, and the open arrow indicates the midline. Scale bar, $250 \mu \mathrm{m}$. limb injections outside the gracile nucleus at any of these ages. These results were, for the most part, confirmed by the study of Wessels et al. (1991), which also employed transganglionic HRP transport. In this study, hindlimb-related afferents could be traced no farther from than the mid-cervical spinal cord on E-17 and did not reach the gracile nucleus until E-18 or later. However, these authors observed very slight labeling in the dorsomedial portion of the rostral cuneate nucleus after tracer injections into the hindlimb in one older rat (postnatal day 9; see their Fig. 9). No evidence of such a projection was seen on the normal side of the brainstem of the adult rats in the present study.

The important point made by the results of both Chimelli and Scaravilli (1987) and Wessels et al. (1991) is that hindlimb afferents normally innervate the gracile nucleus several days after the time at which we amputated the forelimb. It is also likely, but less certain, that our amputations were performed before forelimb afferents reach the cuneate nucleus. The available evidence suggests that this occurs on E-17 (Altman and Bayer, 1984). Thus, the present anomalous sciatic projection appears to result from sciatic afferents invading a territory that they do not innervate during normal development.

It would also appear that the forelimb amputation deprived the cuneate of some part of its normal functional input during the time period when damaged forelimb axons were forming new peripheral connections. Forelimb amputation also permanently removes some of the peripheral input to the cuneate nucleus. It is also possible that fetal forelimb amputation resulted in the death of all ganglion cells whose peripherally directed axonal processes were damaged by the amputation and the projection to the cuneate from the stump is formed by dorsal root ganglion neurons that were not damaged by the amputation. In this regard, it should be noted that Heath et al. (1986) reported that neonatal forelimb amputation reduces the population of dorsal root ganglion cells by $30 \%$.
Expansion of the terminal field of one population of axons when a second population is ablated or otherwise impaired is often cited as evidence for competition between these two populations. While there is clearly room for considerable debate regarding the observations necessary to support the conclusion that interaxonal competition occurs during development (see Guillery, 1988, for a thoughtful review), three phenomena have been consistently observed in systems where such interactions are thought to take place: (1) a period during which afferent axons have more widespread terminal arbors than will be the case in maturity, (2) a resultant overlap among the arbors of axons from different sources such that they converge onto target cells that will ultimately be "dominated" by only one of these inputs, and (3) retention of a wide distribution of axon arbors and functional control over the target cells in question by an afferent input that is given a "competitive advantage" during a critical developmental period. Since the first two of these criteria are not met by developing forelimb and hindlimb afferents, competition, as defined above, does not appear to play a role in the innervation of the appropriate $\mathrm{DCN}$ by forelimb and hindlimb primary afferents.

Smith and Frank (1988) have suggested that the central primary afferent reorganization that follows dorsal root ganglion ablation in bullfrog tadpoles is a secondary result of peripheral axonal sprouting by these same ganglion cells. Changes in the location of the central arbors of these axons are thought to reflect new peripheral targets, and this process is referred to as respecification. Most recently, Mendelson and Frank (1989) demonstrated that removal of the brachial dorsal root ganglion in developing frogs resulted in a small number of neurons in the adjacent dorsal root ganglion "sprouting" into the denervated triceps muscle and corresponding part of the spinal cord. A very important aspect of this was that these primary afferents did not develop abnormally large central arbors, but rather central terminations that were appropriate to their new peripheral tar- 
get. In this context, it is difficult to see how respecification of hindlimb afferents might have occurred in the present experiment. Consistent with this view, the labeled sciatic projections in the cuneate had peripheral axons running through normal locations in the hindlimb. Thus, while we did not record from any sciatic afferents, we think it unlikely that they sprouted in the periphery to innervate portions of the skin normally represented in the cuneate nucleus.

A possible alternative to competition or respecification is that the sciatic ingrowth may reflect an anomalous attraction to the partially deafferented cuneate nucleus. It is now well known that primary afferent neurons are supported by both peripherally and centrally derived neurotrophic factors (e.g., Lindsay and Peters, 1984; Johnson and Yip, 1985; Davies et al., 1986) and that primary afferent neurons maintained in culture will grow toward a source of trophic factor (Gundersen and Barrett, 1979). It may be that the growth of sciatic afferents into the cuneate nucleus represents misdirection of axons toward an "underutilized" source of a centrally derived neurotrophic factor. This explanation resembles a recent proposal that Diamond et al. $(1987,1992)$ have put forward to explain primary afferent axonal sprouting in the periphery toward NGF sources.

One initially puzzling aspect of the data obtained after fetal forelimb removal is that the addition of new central territory for innervation by hindlimb-related axons does not appear to reduce the naturally occurring death of these primary afferent neurons (Killackey and Dawson, 1989). It may be that increasing the central territory available for the axons of these cells with lesions on E-16 is simply too late to influence the number of hindlimb-related ganglion cells that survive the period of naturally occurring cell death. Lumbar dorsal root ganglion cells in rat are born between E-10 and E-13 (Lawson et al., 1974), but the period of naturally occurring cell death for these neurons is not known. However, superior cervical ganglion cells are likely to be born over approximately the same period, and considerable cell death in this population occurs by E-15 (Wright et al., 1983). In this regard, it is also worth noting that Davies and Lumsden (1984) have shown that trigeminal ganglion cell death in mice occurs prior to E-14.

Functional organization in the cuneate nucleus after fetal forelimb removal. Our data from normal rats and the control side of amputated rats indicate that a major portion of the cuneate nucleus is devoted to a representation of the forelimb skin distal to the amputations (see Fig. 6). Following fetal amputation, cells in this portion of the cuneate are not unresponsive to peripheral stimulation, but instead respond to stimulation of skin surfaces overlying the stump and the surrounding shoulder. Given that the cuneate nucleus decreases in size by about one-third, it appears that the representation of the remaining peripheral skin surfaces expands to fill the available territory. This result is similar to that of Kalaska and Pomeranz (1982), who reported that denervation of the kitten paw resulted in many cells with receptive fields on the wrist, forearm, or trunk in the part of the cuneate nucleus in which the paw is normally represented.

Our physiological experiments also provide evidence of a limited functional sciatic input into the altered cuncate nucleus. Nine percent of the unit clusters recorded from the altered cuneate nucleus had receptive fields that included both the skin overlying the stump and portions of the caudal body surface. We also noted several instances of such convergence at the single neuron level. We found no evidence of such convergence in the normal cuneate nucleus. In evaluating these results, it should be kept in mind that our experiments leave some uncertainty with respect to the location of penetrations near the borders of the cuneate nucleus. While careful attempts were made to mark and reconstruct recording sites, the reduced size of the cuneate (its width was less than $250 \mu \mathrm{m}$ in fixed tissue at most levels) made determination of exact recording sites tenuous. Thus, the present results may have underestimated the proportion of recording sites within the cuncate with hindlimb receptive fields.

The most straightforward interpretation of the functional convergence of forelimb and hindlimb inputs in the altered cuneate nucleus is that they reflect the altered projections. However, there appears to be a mismatch between the robustness of our anatomical findings (in five of the seven amputated rats in which the sciatic nerve was labeled, projections to the cuneate nucleus were of the density illustrated in Fig. 3) and the modest evidence of functional convergence. This mismatch is accentuated if one considers that other nerves such as the saphenous contribute to the fasciculus gracilis and may also have altered patterns of projections not labeled in our anatomical experiments. At present, the explanation of this apparent functional masking of hindlimb inputs is unclear. It could involve alterations in the expression or regulation of transmitters endogenous to the cuneate nucleus such as GABA (e.g., Barbaresi et al., 1986) or of inhibitory projections such as those from the raphe nuclei (Steinbusch, 1981). It should also be noted that in other somatosensory structures such as the ventral posterior nucleus, the functional correlates of relatively dense anatomical projections are difficult to detect in normal animals (Rhoades et al., 1987).

Relationship of brainstem changes to cortical organization. The initial aim of the study was to test a proposal made by Killackey and Dawson (1989) to explain an expanded cortical hindlimb representation following fetal forelimb removal. These authors proposed that the enlarged cortical hindlimb representation that they noted could be best explained by an expansion of the terminal territory of gracile afferents into the cuneate nucleus. The present results clearly demonstrate that this does occur, although it is not clear that fetal forelimb removal results in the hindlimb having a larger region of the brainstem devoted exclusively to its representation. However, this may not be relevant to the developmental mechanisms underlying cortical pattern formation. Given our interpretation that the anomalous gracile projection results from a specific attraction to an underutilized neurotropic source, the healthy but anomalous gracile afferents may play a greater role in central pattern formation than the afferents associated with the amputated forepaw even though this input later comes to dominate functionally the altered cuneate nucleus. If the altered cuneate nucleus is the part of the lemniscal pathway ultimately responsible for the increased hindlimb representation demonstrated anatomically in the primary somatosensory cortex, it may follow that this cortical region also contains some representation of the stump of the transected forelimb. Cortical recordings from rats that have sustained forelimb amputations are required to resolve this issue.

\section{References}

Altman J, Bayer SA (1984) The development of the rat spinal cord Adv Anat Embryol 85:1-166.

Barbaresi P, Spreafico R, Frassoni C, Rustioni A (1986) GABAergic neurons are present in the dorsal column nuclei but not in the ventral posterior complex of rats. Brain Res 382:305-326. 
Belford G, Killackey IIP (1979) The development of vibrissae representation in subcortical trigeminal centers of the neonatal rat. $J$ Comp Neurol 188:63-74.

Chimelli L, Scaravilli F (1987) The development of the gracile nucleus in the rat: the time of ingrowth of ascending primary sensory fibers and effect of early deafferentation. Neuroscience 22:661-670.

Davies A, Lumsden A (1984) Relation of target encounter and neuronal death to nerve growth factor responsiveness in the developing mouse trigeminal ganglion. J Comp Neurol 223:124-137.

Davies AM, Thoenen H, Barde Y-A (1986) Different factors from the central nervous system and periphery regulate the survival of sensory neurones. Nature 319:497-499.

Dawson DR, Killackey HP (1987) The organization and mutability of the forepaw and hindpaw representations in the somatosensory cortex of the neonatal rat. J Comp Neurol 256:246-256.

Diamond J, Coughlin M, Macintyre L, Holmes M, Visheau B (1987) Evidence that endogenous $\beta$ nerve growth factor is responsible for the collateral sprouting, but not the regeneration, of nociceptive axons in adult rats. Proc Natl Acad Sci USA 84:6596-6600.

Diamond J, Holmes M, Coughlin M (1992) Endogenous NGF and nerve impulses regulate the collateral sprouting of sensory axons in the skin of the adult rat. J Neurosci 12:1454-1466.

Guillery RW (1988) Competition in the development of the visual pathways. In: The making of the nervous system (Parnavelas JG, Stern CD, Sterling RW, eds), pp 356-379. London: Oxford UP.

Gundersen RW, Barrett JN (1979) Neuronal chemotaxis: chick dorsal root axons turn toward high concentration of nerve growth factor. Science 206:1079-1080.

Heath DD II, Coggeshall RE, Hulsebosch CE (1986) Axon and neuron numbers after forelimb amputation in neonatal rats. Exp Neurol 92: 220-233.

Jacquin MF, Rhoades RW (1985) Effects of neonatal infraorbital lesions upon central trigeminal primary afferent projections in rat and hamster. J Comp Neurol 235:129-143.

Jensen KF, Killackey HP (1987) Terminal arbors of axons projecting to the somatosensory cortex of the adult rat. I. The normal morphology of specific thalamocortical afferents. J Neurosci 7:3529-3543.

Johnson EM Jr, Yip HK (1985) Central nervous system and peripheral nerve growth factor provide trophic support critical to mature sensory neuronal survival. Nature 314:751-752.

Johnson JI, Hamilton TC, Hsung J-C (1972) Gracile nucleus absent in adult opossums after leg removal in infancy. Brain Res 38:421424

Kalaska J, Pomeranz B (1982) Chronic peripheral nerve injuries alter the somatotopic organization of the cuneate nucleus in kittens. Brain Res 236:35-47.

Killackey HP, Belford GR (1979) The formation of afferent patterns in the somatosensory complex of the neonatal rat. J Comp Neurol 183:285-304.

Killackey HP, Dawson DR (1989) Expansion of the central hindpaw representation following fetal forelimb removal in the rat. Eur J Neurosci 1:210-221.

Killackey HP, Jacquin MF, Rhoades RW (1990) Development of somatosensory system structures. In: Development of sensory systems in mammals (Coleman JR, ed), pp 403-429. New York: Wiley.

Land PW, Simons DJ (1985) Metabolic and structural correlates of the vibrissae representation in the thalamus of the adult rat. Neurosci Lett 60:319-324.

Lawson SN, Caddy KWT, Biscoe TJ (1974) Development of rat dorsal root ganglion neurones studies of cell birthdays and changes in mean cell diameter. Cell Tissue Res 153:399-413.

Lindsay RM, Peters C (1984) Spinal cord contains neurotrophic activity for spinal nerve sensory neurons. Late developmental appearance of a survival factor distinct from nerve growth factor. Neuroscience 12:45-51.

Mendelson B, Frank E (1989) Role of competition among sensory neurons in regulation of pattern of innervation at their central and peripheral targets. J Neurophysiol 62:1189-1200.

Mesulam MM (1978) Tetramethyl benzidine for horseradish peroxidase neurohistochemistry. A non carcinogenic blue reaction with superior sensitivity for visualizing neural afferents and efferents. J Histochem Cytochem 26:106-117.

Rhoades RW, Belford GR, Killackey HP (1987) Receptive field properties of rat VPM neurons before and after selective kainic acid lesions of the trigeminal brainstem complex. J Neurophysiol 57:1577-1600.

Smith CL, Frank E (1988) Peripheral specification of sensory connections in the spinal cord. Brain Behav Evol 31:227-242.

Steinbusch HWM (1981) Distribution of serotonin-immunoreactivity in the central nervous system of the rat-cell bodies and terminals. Neuroscience 6:557-618.

Van der Loos H (1976) Barreloids in mouse somatosensory thalamus. Neurosci Lett 2:1-6.

Wall JT, Cusick CG (1984) Cutaneous responsiveness in primary somatosensory (S-I) hindpaw cortex before and after partial hindpaw deafferentation in adult rats. J Neurosci 4:1499-1515.

Welker C (1976) Receptive fields of barrels in the somatosensory neocortex of the rat. J Comp Neurol 166:173-190.

Wessels WJT, Feirabend HKP, Marani E (1991) Development of projections of primary afferent fibers from the hindlimb to the gracile nucleus: a WGA-HRP study in the rat. Dev Brain Res 63:265-279.

Wong-Riley $M$ (1979) Changes in the visual system of monocularly sutured or enucleated cats demonstrable with cytochrome oxidase histochemistry. Brain Res 160:134-138.

Woolsey TA (1990) Peripheral alteration and somatosensory development. In: Development of sensory systems in mammals (Coleman JR, ed), pp 461-516. New York: Wiley.

Woolsey TA, Van der Loos H (1970) The structural organization of layer IV in the somatosensory region (SI) of the mouse cerebral cortex. Brain Res 17:205-242.

Woolsey TA, Wann JR (1976) Areal changes in mouse cortical barrels following vibrissal damage at different postnatal ages. J Comp Neurol 170:53-66.

Wright LL, Cunningham TJ, Smolen AJ (1983) Developmental neuron death in the rat superior cervical sympathetic ganglion: cell counts and ultrastructure. J Neurocytol 12:727-738. 